\title{
Impelling and Inhibiting Forces in the Perpetration of Intimate Partner Violence
}

\author{
Eli J. Finkel \\ Northwestern University
}

\begin{abstract}
The huge corpus of research identifying risk factors for intimate partner violence (IPV) has outpaced theoretical models explaining how these risk factors combine to exert their effects. This report presents a 2 -stage process model investigating how a previously nonviolent interaction between intimate partners escalates to IPV. The first stage examines whether at least one partner experiences strong violence-impelling forces, which lead the individual to experience action tendencies toward IPV. The second examines whether the partner experiencing violence-impelling forces suffers from weak violence-inhibiting forces, which would otherwise serve to override such action tendencies. This model extends previous research by emphasizing the importance of inhibitory processes in IPV and by imposing a new conceptual structure on the identified IPV risk factors.
\end{abstract}

Keywords: impelling/inhibiting model, intimate partner violence, domestic violence, aggression, self-regulation

Spouse A and Spouse B have been married for two years. They have been arguing lately, and anger toward one another has become a pervasive, simmering presence. This past Friday night, anger boiled over into fury. In a rage, Spouse A picked up a lamp, intending to throw it at Spouse B. Moments after this violent impulse struck Spouse A, however, a powerful inhibitory force emerged to override it. Spouse A placed the lamp back on the table and stormed out of the house in a profanity-laced tirade.

This scenario provides a dramatic illustration of a common but largely neglected phenomenon relevant to intimate partner violence (IPV): Partners sometimes experience violent impulses toward one another without enacting violent behavior. Evidence suggests that experiencing

I gratefully acknowledge Candida Abrahamson, Galen Bodenhausen, Paul Eastwick, Chris Eckhardt, Rich Felson, Wendi Gardner, Steve Graham, Madoka Kumashiro, Mike Johnson, George Loewenstein, and Deb Small for their helpful feedback. I also thank the Center for Advanced Study in the Behavioral Sciences in Palo Alta, CA, for providing a stimulating intellectual environment for playing with the ideas presented in this article.

Correspondence concerning this article should be addressed to Eli J. Finkel, Northwestern University, Department of Psychology, 2029 Sheridan Road, Swift Hall \#102, Evanston, IL 60208-2710. E-mail: finkel@ northwestern.edu the occasional violent impulse toward a romantic partner may not be the sole province of a group of patriarchal or pathologically deviant men. I argue that many individuals, both men and women, experience violent impulses on rare occasion, but that these individuals are frequently able to manage such impulses in a way that prevents violent behaviors. A more complete understanding of IPV will likely emerge if scientists devote greater attention to investigating, and explicitly distinguishing between, processes that cause individuals to (a) experience violent impulses toward their partner and (b) refrain from perpetrating violent acts when such impulses arise. The goals of this report are to emphasize the importance of these violenceinhibiting processes and to provide a conceptual framework for organizing IPV risk factors.

Intimate partner violence ${ }^{1}$ (IPV) refers to any behavior carried out with the primary proximal

\footnotetext{
${ }^{1}$ Although many psychologists (e.g., Anderson \& Bushman, 2002) distinguish between the terms "violence" and "aggression" (with the former term limited to acts intended to cause extreme harm and the latter being general enough also to include acts intended to cause less harm), most empirical articles in the IPV literature do not allow for clear demarcations between these two constructs. I use the term violence rather than aggression because it is much more prevalent in the IPV literature; I use the term aggression when reviewing the work of scholars who employ that
} 
intent to cause physical harm to a romantic partner who is motivated to avoid being harmed (see Baron \& Richardson, 1994). ${ }^{2}$ The strength of violence-impelling forces is determined by the collective power of the variables that cause the individual to experience action tendencies toward IPV, and the strength of violenceinhibiting forces is determined by the collective power of the variables that cause the individual to override these violence-impelling forces in favor of nonviolent behavior. The literature on IPV has generally neglected this distinction between risk factors that impel violence and those that disinhibit it.

\section{Incidence Rates, Gender, and Two Forms of Intimate Partner Violence}

Dozens of large-scale surveys exploring how individuals deal with conflict in their intimate relationships reveal that individuals enact violent behaviors against marital and dating partners with alarming frequency (e.g., Magdol et al., 1997; McLaughlin, Leonard, \& Senchak, 1992; Straus, 2004). Large-scale representative surveys in the United States, for example, indicate that approximately 1 out of every 6 couples experiences at least one act of IPV every year (Schafer, Caetano, \& Clark, 1998; Straus \& Gelles, 1986). Such high estimates are comparable with or even lower than those from additional surveys from the United States and from around the world (e.g., Magdol et al., 1997; Straus, 2004). These investigations have been referred to as "family conflict studies" because investigators typically present the survey to research participants in terms of how partners deal with conflict in their relationships.

"Crime studies" differ from family conflict studies in that investigators typically present the survey to research participants in terms of crime, crime victimization, personal safety, injury, or violence (e.g., Bureau of Justice Statistics, 1997; Tjaden \& Thoennes, 2000). These studies reveal a substantially lower prevalence of the number of couples experiencing IPV in a given year, frequently less than $1 \%$ (see Straus, 1999). Moreover, whereas estimates from family conflict studies indicate that approximately $1-3 \%$ of violent acts result in injury, estimates from the crime studies indicate that $50-75 \%$ of them do (Straus, 1999). Taken together, these results suggest that (a) physically violent acts carried out against romantic partners are disturbingly common, (b) most of these acts are not encoded by the perpetrator or by the victim as crimes or as threats to personal safety, and (c) both types of violence lead to a substantial number of injuries every year, although any given act assessed in a family violence study is much less likely to result in injury than is any given act assessed in a crime study.

Family conflict studies and crime studies also reveal divergent pictures regarding gender differences in the rates of IPV. Family conflict studies generally reveal that men and women are approximately equally likely to perpetrate acts of IPV. In fact, a meta-analytic review of 82 studies (with a preponderance in the family conflict tradition) suggests that women may even be more likely than men to perpetrate, although this gender difference is miniscule (Archer, 2000). Crime studies, in contrast, reveal that IPV is perpetrated by men much more frequently than by women with some estimates suggesting that more than $90 \%$ of the acts of IPV are carried out by men (see Straus, 1999). Overall, the literature suggests that men and women perpetrate acts of IPV at near-equal rates, although there is a rare, severe form of IPV that is perpetrated predominantly by men and that is especially likely to show up in crime statistics.

This identification of two forms of violence echoes Johnson's (1995, in press, Johnson \& Ferraro, 2000) distinction between situational couple violence and intimate terrorism (formerly labeled "common couple violence" and "patriarchal terrorism," respectively; Johnson, 1995). The critical difference between these two forms is that situational couple violence emerges sometimes when conflict situations get out of hand, whereas intimate terrorism is perpetrated in the interest of asserting dominance and control in the relationship. Both forms can, in extreme cases, result in injury or even death,

term, but the two terms are not intended in this report to distinguish between distinct phenomena.

${ }^{2}$ This report focuses exclusively the initiation of violence in a specific social interaction that had theretofore been nonviolent. It does not examine IPV as self-defense, nor does it also does examine psychological or sexual aggression. Also, defining IPV in terms of the proximal intent to cause harm does not contradict the notion that many acts of IPV are also motivated in part by distal goals (e.g., to influence the partner's behavior in the long-run). 
although such outcomes are much more common in intimate terrorism. As Johnson (1995) observes, the discrepant methods employed in family conflict studies (e.g., data collection from nationally representative surveys and convenience samples) versus crime studies (e.g., data collection from hospitals and battered women's shelters) likely lead investigators employing the former methods primarily to examine situational couple violence and investigators employing the latter methods primarily to investigate intimate terrorism. Johnson's typology makes no a priori assumptions about sex differences in IPV, instead viewing the existence and degree of such differences as issues to be resolved empirically. Empirical evidence reveals that intimate terrorism is perpetrated predominantly by men (Johnson, in press), whereas situational couple violence is perpetrated at slightly higher rates by women (Archer, 2000; Johnson, 1995; Straus, 1999; but see Ehrensaft, Moffitt, \& Caspi, 2004, for evidence that even severe IPV is perpetrated at near-equal rates by men and women).

Although large-scale studies have now been conducted in sufficient numbers to draw conclusions regarding the prevalence rates and gender differences described above, a serious limitation of the existing literature is that many scholars' a priori assumptions of gender differences have caused them to collect data on and build theoretical models of only male-to-female IPV, generally ignoring female-to-male IPV. Working from the assumption that gender differences must be demonstrated rather than assumed (see Felson, 2002), I strive to build a model of IPV that is gender neutral in its general structure but sufficiently flexible to accommodate scholars' predictions regarding gender differences. This model is also intended to be expansive enough to include phenomena studied in both family conflict studies (typically situational couple violence) and crime studies (typically intimate terrorism).

\section{Impelling and Inhibiting Forces in Intimate Partner Violence}

Researchers have been remarkably successful in identifying risk factors for (correlates of) IPV (see Schumacher, Feldbau-Kohn, Slep, \& Heyman, 2001; Straus, Gelles, \& Steinmetz, 1980), but little consensus has emerged to ex- plain the interplay among them, and "theory and research on relationship violence remain uncohesive" (Berscheid \& Regan, 2005, p. 52). I suggest that one organizational framework for integrating the dizzying array of risk factors (which are selectively reviewed below) is to determine the degree to which each of them (a) strengthens violence-impelling forces, (b) weakens violence-inhibiting forces, or (c) does both. Among other benefits, this framework will facilitate the cross-fertilization of ideas between the IPV literature and the burgeoning selfregulation literature (see Baumeister \& Vohs, 2004), with self-regulation defined as "the many processes by which the human psyche exercises control over its functions, states, and inner processes" (Baumeister \& Vohs, 2004, p. 1). Any time individuals want to initiate a new behavior or override an impulse, for example, they invoke self-regulatory processes. Although such processes are clearly relevant in the circumstances preceding acts of IPV - and they may dictate to a large extent whether violent impulses are manifested in violent behaviors rather then being restrained-they have been largely neglected by IPV researchers.

Individuals will only perpetrate IPV when the violence-impelling forces they experience at that time exceed the violence-inhibiting forces, an observation that focuses the Impelling/ Inhibiting Model primarily on interaction effects. For example, strengthening violenceimpelling forces will not lead to greater tendencies toward violent behavior unless these forces exceed violence-inhibiting forces. Once violence-impelling forces surpass violence-inhibiting forces, however, the individual will perpetrate IPV. In addition, further strengthening these already-above-threshold violence-impelling forces will tend to increase the severity of the violence acts, in terms of both their type (e.g., slapping vs. punching) and their intensity (e.g., a weak punch vs. a strong punch). It is important to recognize that although the example presented in this paragraph has examined dynamic impelling forces and static inhibiting forces (i.e., the former changes while the latter does not), the inverse situation is also tenable, as is the (perhaps most frequent) situation in which both sets of forces fluctuate simultaneously.

This analysis makes clear that violenceinhibiting forces play an important role in pre- 
dicting whether individuals perpetrate IPV, a perspective differing from key aspects of many prominent theoretical treatments of the topic. Many scholars have argued, for example, that IPV runs rampant at least in part because society condones it, with some going so far as to call the marriage license a "hitting license" for both men and women (Straus et al., 1980) and others arguing that only male-to-female IPV is viewed as legitimate (e.g., R.E. Dobash \& R.P. Dobash, 1979). These theoretical treatments seem to imply that there are common social roles (occupied by "normal" individuals rather than just by the emotionally unbalanced fringe of society) that largely remove violence inhibiting forces. Following Felson (2002), I suggest an alternative explanation for the strikingly high rates of IPV emerging from family conflict studies: the frequency of IPV reflects the high levels of interdependence that romantic partners experience with one another, which renders conflict "an inevitable - though often unanticipatedfeature of close relationships. The strong, frequent, and diverse bonds between [intimate partners] set the stage for conflicting interests to surface" (Holmes \& Murray, 1996, p. 650). Given that violent disputes typically begin with verbal conflict (Felson, 1984; Murphy \& O'Leary, 1989; Stets, 1990), it is perhaps not surprising that the elevated opportunities for nonviolent conflict that occur within highly interdependent relationships predict higher levels of IPV. In addition, elevated interdependence increases the motivation to influence the partner's behavior because that behavior strongly influences one's own outcomes (Felson, 2002; Thibaut \& Kelley, 1959). In short, violent impulses may well emerge more frequently and more powerfully toward intimate partners than toward other individuals in large part because of the strong interdependence characteristic of such partnerships.

However, although experiencing violent impulses certainly increases the probability that individuals will perpetrate IPV, this association between violent impulses and violent behaviors is far from absolute. Under many (and likely most) circumstances, violent impulses do not lead to violent behaviors. One recent study systematically distinguished IPV impulses from IPV behaviors by having university students (a) recall the most severe fight they had ever experienced with a romantic partner and (b) report on the degree to which they were tempted to enact a series of violent behaviors and the degree to which they actually enacted these behaviors (Finkel, 2006). Participants reported significantly stronger violent impulses than violent behaviors, which seems to signify that these students implemented some form of behavioral restraint to override their violent impulses.

Other recent findings also hint at the importance of violence-inhibiting forces in preventing IPV in highly interdependent relationships (Felson, Ackerman, \& Yeon, 2003). This study demonstrated that although verbal altercations were much more frequent among spouses than among strangers, such altercations were three times more likely to lead to violence among strangers than among spouses. One plausible interpretation of these findings is that verbal conflict is especially common between intimate partners and leads to elevated levels of IPV, but that any given verbal conflict between them is much less likely than one between strangers to lead to violence. To illustrate, imagine that James had 20 arguments with his wife and 3 arguments with strangers last year. Imagine further that he enacted violent behavior in 4 of his arguments with his wife and in 1 of his arguments with strangers. This means that James was 4 times more likely to perpetrate a violent act against his wife than against a stranger (4 vs. $1)$, even though the likelihood of him enacting violent behavior in any given argument was much higher with strangers (1 out of 3 , or $33 \%$ ) than with his wife (4 out of 20, or 20\%).

Taken together, the results of these studies lead to the conclusion that individuals may be especially likely to override violent impulses in their intimate relationships, a pattern that contradicts the notion that involvement in such relationships is accompanied by the beliefs that violent behavior is acceptable. The interdependence characterizing intimate relationships may render individuals especially susceptible to experiencing strong violence-impelling forces, but this same interdependence also seems to function on many occasions to strengthen violenceinhibiting forces.

The Impelling/Inhibiting Model of Intimate Partner Violence Perpetration

In an effort to impose coherence on the huge array of risk factors identified by IPV research- 
ers, I propose in Figure 1 the Impelling/ Inhibiting Model of Intimate Partner Violence Perpetration. This model identifies the two central questions researchers must ask regarding a given interaction between romantic partners to determine whether IPV will transpire. First, does at least one partner experience strong violence-impelling forces? And second, is that partner characterized at that time by weak violence-inhibiting forces? If the answer to both questions is yes, then the individual is likely to perpetrate IPV; if the answer to at least one question is no, the individual is unlikely to do so. In Figure 1, the "structural part" of the Impelling/Inhibiting Model is depicted inside the horizontal rectangle at the bottom of the figure, whereas the risk factors for strong violence-impelling forces and weak violenceinhibiting forces are depicted inside the tall, dotted boxes at the top of the figure. The "risk

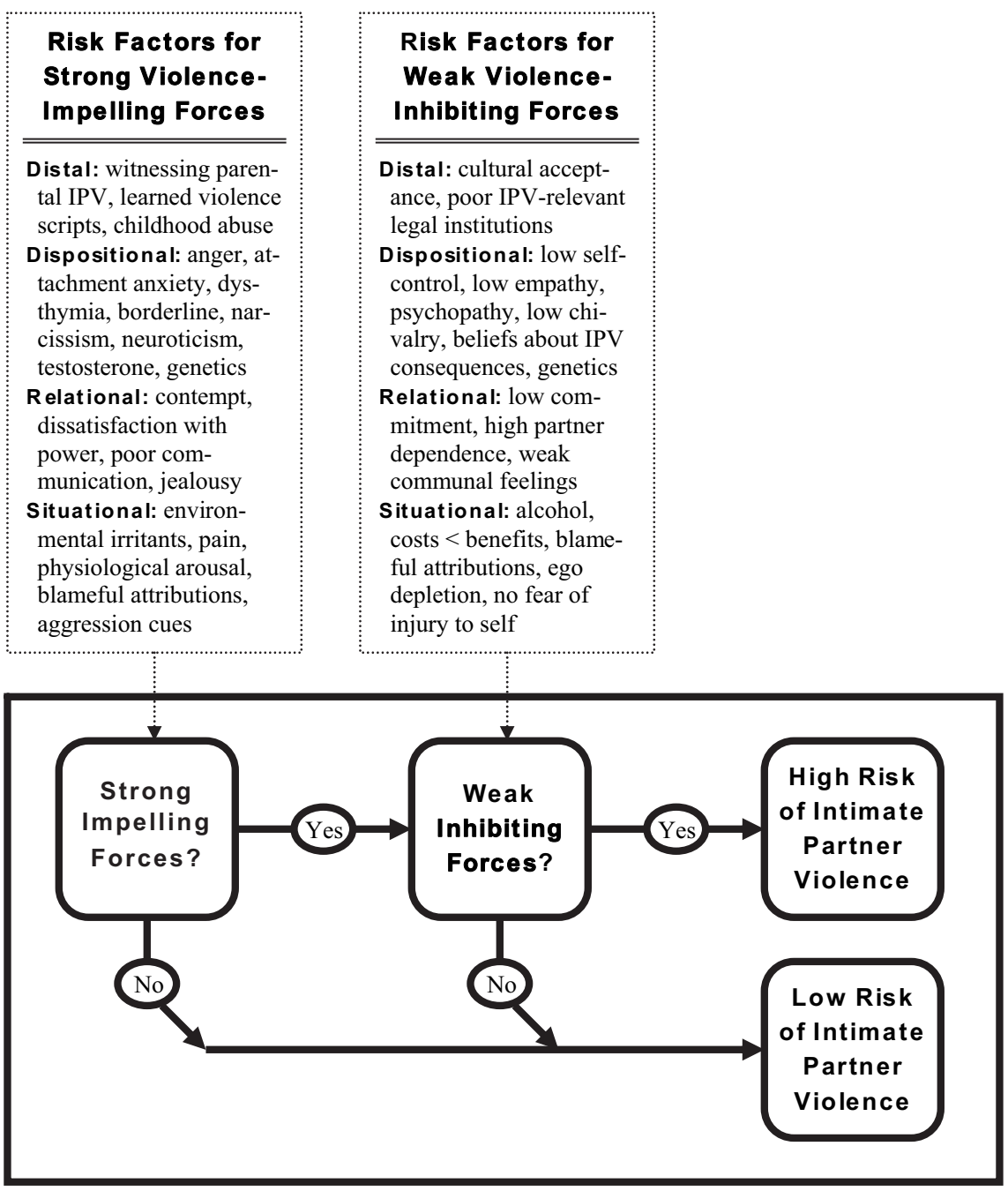

Figure 1. The Impelling/Inhibiting Model of Intimate Partner Violence Perpetration and Risk Factors that Exacerbate or Curtail the Pathway to Violence. The Impelling/Inhibiting Model is depicted inside the large, horizontal rectangle at the bottom of the figure. The tall, rectangular boxes at the top identify risk factors relevant to intimate partner violence and are illustrative rather than exhaustive. The classification of a given risk factor into one category does not necessarily mean that it has no relevance to the other category. 
factors part" consists of empirically demonstrated and/or theoretically derived predictors; these predictors are intended to be illustrative rather than exhaustive. The structural part of the model (which is akin to the hardware of a computer) will remain constant across all theories of IPV, whereas the risk factors part (which is akin to the software) will vary considerably depending upon the specific research questions under investigation.

Before discussing violence-impelling and violence-inhibiting forces in greater detail, two observations are in order. First, although many risk factors will fit cleanly into one of the two categories (violence-impelling or violenceinhibiting forces), others will influence both stages in the process. In other words, if a particular variable is a violence-impelling risk factor, this does not necessarily imply that it has no influence on violence-inhibiting processes, or vice versa. Second, the Impelling/Inhibiting Model is intended to apply to those circumstances in which at least one partner has already experienced an instigating trigger (e.g., perceived partner provocation or goal obstruction, activation of the desire to control the partner's behavior; Berkowitz, 1993; Dollard, Doob, Miller, Mowrer, \& Sears, 1939; Felson, 1993, 2002), thereby situating violent behavior within the realm of possibility. In the absence of an instigating trigger (e.g., when placidly watching TV with the partner), violence-impelling and violence-inhibiting forces are largely irrelevant.

\section{Violence-Impelling Forces}

The Impelling/Inhibiting Model applies to a given social interaction between romantic partners and begins at the left of Figure 1 by asking whether at least one partner experiences strong violence-impelling forces. A core proposition of the model is that many of the variables predicting IPV function by strengthening the action tendencies toward violent behavior, whereas others do so by weakening the propensity to restrain these tendencies. The vertical rectangular box at the top-left of Figure 1 presents an illustrative series of risk factors that I hypothesize function primarily as impelling forces. To impose enhanced theoretical coherence on these risk factors, I divide them into distal, dispositional, relational, and situational categories. The distal category includes ontogenic factors, cul- tural and subcultural norms, and socioeconomic and demographic factors. The dispositional category includes personal dispositions, interpersonal dispositions, biological factors, and attitudes and beliefs that are relatively stable over time. The relational category includes those characteristics of the romantic relationship that are separate from each partner's distal or dispositional characteristics. Finally, the situational category includes temporary cognitive, affective, and physiological experiences emerging from features of the current situation. In the ensuing paragraphs, I provide illustrative discussions of one violence-impelling factor (and, subsequently, one violence-inhibiting factor) from each of these categories.

One potentially important distal risk factor for strong violence-impelling forces emerges from social learning processes (Bandura, 1973). Abundant evidence suggests that children who witnessed interparental violence (either fatherto-mother or mother-to-father violence) during childhood are at elevated risk of perpetrating IPV in adulthood (Kwong, Bartholomew, Henderson, \& Trinke, 2003; Schumacher et al., 2001; Stith et al., 2000; Straus et al., 1980). Social learning processes can influence how individuals (a) attend to and interpret social cues, (b) search their memories for available behavioral scripts, and (c) evaluate whether or not each of these scripts is appropriate to the situation (Huesmann, 1988). Through one or more of these pathways, individuals who have learned violent scripts during development are likely to experience stronger action tendencies toward IPV than will those who have learned nonviolent scripts. In addition, the content of these violent scripts is likely to influence the nature of any violent behavior (e.g., slapping, punching, stabbing) facilitated by them.

One potentially important dispositional risk factor for strong violence-impelling forces is anger. A recent meta-analytic review reveals that trait anger tendencies exhibit moderately strong positive associations with IPV (at least among men; women were not studied), regardless of whether perpetrators of IPV are compared to nonviolent men in general or to relationship-discordant nonviolent men (Norlander $\&$ Eckhardt, 2005). In addition, men who perpetrate severe IPV tend to exhibit moderately higher trait anger tendencies than do men who perpetrate less severe IPV. Despite this robust 
association between trait anger tendencies and IPV, evidence and common sense strongly suggest that the experience of anger in a given situation frequently does not lead to violent behavior (Averill, 1982; Tavris, 1989), a fact that caused Norlander and Eckhardt (2005, p. 122) to conclude that, "[d]isturbances in anger arousal are therefore likely to be related to aggressive behavior only in the context of other factors of theoretical and practical relevance." The Impelling/Inhibiting Model imposes theoretical coherence on this assertion: anger is likely to exhibit especially strong associations with IPV when violence-inhibiting forces are weak (see Baumeister \& Boden, 1998).

One potentially important relational risk factor for strong violence-impelling forces relates to dissatisfaction with relationship-specific power/control dynamics. Although the contradictory literature regarding the association of the existence of power imbalances in the relationship and IPV does not allow for firm conclusions about the direction of any possible effects (e.g., Hotaling \& Sugarman, 1986; Straus et al., 1980), dissatisfaction with power in the relationship predicts elevated tendencies toward IPV (at least among men; women were not studied); this effect was partially mediated through elevated tendencies toward psychological aggression perpetration (Ronfeldt, Kimerling, \& Arias, 1998). Results from a second study revealed that violent husbands with low decision-making power in the relationship perpetrate more severe IPV than do violent husbands with high decision-making power (Babcock, Waltz, Jacobson, \& Gottman, 1993).

The conclusion that dissatisfaction with one's level of power in the relationship predicts IPV must be tempered by the fact that this research has been conducted only within the context of male-to-female violence. Although most risk factors may well predict IPV similarly for men and women, these power processes could plausibly represent an exception. Relative deprivation dynamics (see Runciman, 1966; Walker \& Smith, 2002) in which individuals might compare their level of power in the relationship to the level afforded to their same-sex parent in his or her own marriage could render dissatisfaction with relationship power more upsetting for men than for women. Investigating such potential gender differences is an important topic for future research.
In general, relational risk factors for violence-impelling forces tend to relate broadly to dissatisfaction or conflict. In this respect, I echo the observation that "[c]onflict is an inevitable part of all human association, whereas violence as a tactic to deal with conflict is not" (Straus, Hamby, Boney-McCoy, \& Sugarman, 1996, p. 284). Conflict, I suggest, not infrequently leads to violent impulses, but violent behavior can frequently be averted when violence-inhibiting forces are strong.

One potentially important situational risk factor for strong violence-impelling forces involves attributions or appraisals of the partner's behavior in the immediate situation (for a review, see Eckhardt \& Dye, 2000). Results from one study employing hypothetical problematic marital vignettes revealed that maritally violent men were more likely than both maritally distressed but nonviolent men and maritally nondistressed and nonviolent men to conclude that their wife had acted with negative intent in the vignettes (e.g., that she was deliberately trying to be hurtful or insulting; Holtzworth-Munroe \& Hutchinson, 1993; see also Eckhardt, Barbour, \& Davison, 1998). Although such attributions certainly emerge in part from stable individual differences (see work on the "hostile attribution bias" by Dodge \& Coie, 1987), two lines of evidence suggest that they also emerge in part from the features of the specific situation. First, the maritally violent men, relative to other men, attributed greater negative intent to their wife in some vignettes (e.g., those involving jealousy or being rejected by their wife) but not in others (e.g., those in which the wife was being demanding; Holtzworth-Munroe \& Hutchinson, 1993). Second, recent findings have called into question the degree to which individuals have enduring attributional styles in their romantic relationships, instead suggesting that attributional tendencies change over time (Karney \& Bradbury, 2000). Although additional research is required before drawing firm conclusions about the degree to which individuals who perpetrate IPV have enduring attributional styles, there is ample reason to suggest that the specific attributions partners make about one another's behavior in the present situation include nondispositional components that will influence the strength of their violenceimpelling forces. 


\section{Violence-Inhibiting Forces}

Moving to the right in Figure 1, the Impelling/Inhibition Model suggests that some risk factors predict weak violence-inhibiting forces instead of (or in addition to) predicting strong violence-impelling forces. These violenceinhibiting forces decrease the propensity to override action tendencies toward violent behavior (i.e., they disinhibit violent tendencies). The vertical rectangular box at the top-center of Figure 1 presents an illustrative series of risk factors that I hypothesize function primarily by weakening violence-inhibiting forces. As I did with the risk factors for strong violenceimpelling forces, I divide these risk factors for weak violence-inhibiting forces into distal, dispositional, relational, and situational categories.

One potentially important distal risk factor for weak violence-inhibiting forces is relative cultural approval of IPV. A study of Hispanic Americans, for example, showed that rates of IPV (at least among men; women were not studied) covaried with approval of this type of violence (Kaufman Kantor, Jasinski, \& Aldarondo, 1994; also see Archer, 2006). Whereas Puerto Rican husbands had both the highest rates of approval of IPV $(18.8 \%)$ and the highest rate of IPV perpetration (20.4\%), Cuban husbands had both the lowest rates of approval of IPV $(2.1 \%)$ and the lowest rate of IPV perpetration $(2.5 \%)$. These results suggest that cultures vary substantially in the degree to which their members approve of IPV, and those cultures with high levels of approval exhibit greater tendencies toward IPV than do those with low levels. It is worth noting, however, that greater than $80 \%$ of the men in all four Hispanic subcultures studied disapproved of IPV.

One potentially important dispositional risk factor for weak violence-inhibiting forces is low self-control (see Baumeister, Heatherton, \& Tice, 1994; Gottfredson \& Hirschi, 1990). Whereas acting on the basis of gut-level violent impulses is relatively easy, inhibiting these violent impulses requires effort. Individuals must exert "self-control" and reduce their dependence on the "stimulus control" (Metcalfe \& Mischel, 1999) exerted on them by the instigating trigger that inspires violence-impelling forces. Although violent impulses may dissipate rapidly if individuals stop to take inventory of the situation, these impulses could well lead directly to violent behaviors in the absence of sufficient ability or motivation to take such inventory. Consistent with the assertion that "breakdowns in self-control processes are the proximate causes of the majority of violent and aggressive actions that occur spontaneously in peacetime society" (Baumeister \& Boden, 1998, p. 111), research has established low selfcontrol as a risk factor for relationshipdestructive nonviolent (Finkel \& Campbell, 2001) and violent (Finkel \& Foshee, 2006) conflict-based behavior. When facing conflictual circumstances, dispositional factors such as self-control help individuals to enact "behaviors that break the momentum of a cycle, or play an 'editing function.' The ability of one or both partners to play this role depends on their being able to step back cognitively and achieve a broader, more positive perspective on localized events, to effectively overcome the myopia resulting from the heat of the moment" (Holmes \& Murray, 1996, p. 624).

One potentially important relational risk factor for weak violence-inhibiting forces is low relationship commitment. Although there is some evidence that IPV and relationship duration are positively associated (e.g., Stets \& Pirog-Good, 1987), research suggests that experiencing strong psychological commitment to one's relationship predicts a reduced likelihood of perpetrating IPV (Gaertner \& Foshee, 1999). In fact, relationship duration and psychological commitment exhibit significant unique associations with the likelihood of perpetrating IPV, with the former effect positive and the latter negative (Gaertner \& Foshee, 1999). A plausible explanation for this pattern of findings is that whereas longer relationship durations are associated with increased access to and interdependence with the partner (factors that are likely to increase the odds of IPV), greater commitment serves as a violence-inhibiting force that helps individuals avoid enacting violent behavior in those situations where they experience an action tendency to do so.

One potentially important situational risk factor for weak violence-inhibiting forces is alcohol consumption. For example, a prospective daily diary study demonstrated that IPV (at least among men; women were not studied) is approximately 10 times more likely on days when the perpetrator drank alcohol than on days when 
he did not, even after controlling for relationship well-being and his general alcoholic tendencies (Fals-Stewart, 2003). This study also revealed that heavy drinking was an especially strong predictor, with the likelihood of IPV being approximately 18 times higher on days where the perpetrator drank heavily than on days when he did not drink at all. Yet another finding was that greater than $60 \%$ of violent episodes involving perpetrator alcohol consumption took place within 2 hours of his drinking, and greater than $80 \%$ occur within 4 hours. These results are consistent with Steele's alcohol myopia theory (e.g., Steele \& Josephs, 1990; for a review and integration of theories exploring the alcohol-aggression link, see Giancola, 2000), which suggests that alcohol predicts elevated levels of violent behavior primarily by impairing the cognitive processes that otherwise would combat violence-impelling forces. Alcohol is unlikely to increase the likelihood or severity of IPV among individuals who experience no violence-impelling forces, but it is likely to increase the likelihood or severity of IPV among individuals who are experiencing strong violence-impelling forces. Individuals who resent that their partner has rejected their sexual overtures, for example, are likely to attend every bit as closely to this salient cue when they are drunk as when they are sober, but they are much less capable when drunk of attending to strong cues that require further cognitive processing (e.g., the long-term repercussions of perpetrating IPV).

\section{Additional Features of the Impelling/Inhibiting Model}

The Impelling/Inhibiting Model depicted in Figure 1 is intended to provide a plausible process-oriented account of intimate partner violence with the potential to impose enhanced theoretical coherence on the risk factors for IPV perpetration. Before concluding the presentation of this model, I highlight three of its additional features. First, both violence-impelling forces and violence-inhibiting forces are frequently activated simultaneously, which can leave the individual in a state of inner tension between indulging versus overriding violent impulses. This situation parallels that described by Baumeister and colleagues (1994, p. 9) in their discussion of self-regulatory challenges: "[P]eople feel as if there is an inner conflict going on, in which they are pulled in opposite directions." Second, the model is extremely flexible, allowing researchers to determine which variables (e.g., gender, anger, selfcontrol) are most relevant for their specific research questions and to incorporate their own theory of IPV within its more general framework. Third, I have heretofore focused on each of the model's components (either violenceimpelling or violence-inhibiting forces) in isolation from the other one, an approach that presents an idealized picture in which all other variables are held constant when discussing any given predictor. Although this idealized picture is useful for explanatory purposes, it (along with almost all published research) ultimately fails to capture the complexity of IPV. A strength of the Impelling/Inhibiting Model is that it suggests a large number of immediately accessible moderational hypotheses.

One empirical example of research linking together different components of the model employed a sample of 15 to17-year-old high school students who completed scales assessing violence-impelling forces (e.g., attachment anxiety, dysthymia), a central violence-inhibiting force (expectations of negative consequences of perpetrating IPV), and the frequency of their IPV perpetration over the previous year (Finkel $\&$ Foshee, 2006). Attachment anxiety refers to emotional preoccupation with and fear of rejection by significant others (cf. Hazan \& Shaver, 1987) and is an established risk factor for IPV perpetration (see Bartholomew \& Allison, 2006). Dysthymia, or depressed affect, refers to the subjective experience of feeling unhappy or hopeless about the future (Kandel \& Davies, 1982) and is likewise an established risk factor for IPV perpetration (e.g., Magdol et al., 1997). Significant interaction effects revealed that the violence-impelling forces predicted greater perpetration among participants who weakly expected negative consequences of perpetrating (weak inhibiting forces), but they generally were not associated with perpetration among those who strongly expected such consequences (strong inhibiting forces). These interaction effects are precisely what the Impelling/Inhibiting Model predicts (see Figure 1). 
Implications of the Impelling/Inhibiting Analysis

I briefly discuss three implications of Impelling/Inhibiting Model depicted in Figure 1. First, this model (a) explicitly emphasizes that many (perhaps even most) individuals occasionally experience impulses to enact IPV and (b) underscores the importance of violenceinhibiting forces in overriding these impulses (see Finkel \& Foshee, 2006). If the model proves fruitful across diverse constructs and laboratories, this would suggest that the field could benefit considerably by complementing research aimed at answering questions such as "What makes individuals perpetrate IPV?" with research aimed at answering questions such as "What makes individuals effective at overriding violent impulses toward their partner?" and "How can educators, clinicians, and policymakers help individuals strengthen their violenceinhibiting tendencies?" A great deal of evidence suggests that an important culprit underlying criminal and self-defeating behavior is a failure to restrain our impulses (Baumeister et al., 1994; Gottfredson \& Hirschi, 1990), and training individuals to regulate their impulses is likely to be a more successful intervention than training them not to experience those impulses in the first place (Baumeister, 2005). As mentioned previously, the self-regulation literature (see Baumeister \& Vohs, 2004) has been largely neglected by IPV researchers. Increased emphasis on violence-inhibiting processes could significantly advance theoretical analyses of IPV and could well lead to superior clinical interventions to curtail IPV perpetration; most extant interventions are notoriously ineffective (Babcock, Green, \& Robie, 2004; Dutton \& Corvo, 2006).

A second implication is that the Impelling/ Inhibiting Model has the potential to impose theoretical coherence on the vast array of IPV risk factors, helping to identify some as risk factors for strong violence-impelling forces and others as risk factors for weak violenceinhibiting forces-and still others as risk factors for both. Of course, the current state of the literature does not allow for definitive assignments of risk factors to these categories, so those presented in Figure 1 are tentative; firm conclusions await future empirical research explicitly designed to examine the degree to which certain risk factors increase the odds of IPV perpetration by strengthening violent impulses or by weakening the tendency to override these impulses.

A third implication is that the Impelling/ Inhibiting Model could inform aggression theories more generally. Although the focus in the present report has been on violent or aggressive behavior within intimate partnerships, the core structure of the model (see Figure 1) could well apply to such behavior in other interpersonal contexts as well. I observed previously that the IPV literature has largely neglected recent advances in research on self-regulation; a similar criticism has been levied recently on the interpersonal aggression literature more generally: "Most theories of aggression largely ignore the role that self-regulation plays in aggressive behavior" (Bettencourt, Talley, Benjamin, \& Valentine, 2006, p. 753). Perhaps the Impelling/ Inhibiting Model could be adapted to inform our understanding of phenomena as diverse as playground brawls, drive-by shootings, and aggression as it is manifested in laboratory-based experiments.

\section{Directions for Future Research}

The present report leads to a number of directions for future research, including the following six. First, in contrast to the enormous efforts that have gone into identifying risk factors for IPV perpetration, the role of violenceinhibiting forces in IPV perpetration processes has been relatively neglected. Mining the selfregulation literature for insights into impulse inhibition processes provides one promising avenue for future research, and this literature comes equipped with valuable theoretical and empirical tools that could be adapted easily for use by scholars interested in IPV. As one example, recent research emphasizing that a broad and depletable resource underlies acts of selfregulation (Muraven \& Baumeister, 2000) has now been applied to aggressive behavior against strangers: individuals who experienced a manipulation that depleted their self-regulatory resources, compared to individuals whose self-regulatory resources were not depleted, manifested elevated aggressive tendencies (DeWall, Baumeister, Gailliot, \& Stillman, 2007). It seems plausible that similar depletion dynamics emerge outside the laboratory, influencing 
the likelihood that individuals who experience violent impulses toward their partner will fail to restrain these impulses.

Second, the Impelling/Inhibiting Model discusses the processes underlying IPV perpetration in terms of interaction effects. Although establishing main effect predictors of IPV perpetration remains a valuable endeavor, a greater emphasis on moderational models will surely yield new insights into the psychological processes that precede both violent and nonviolent behavior (for one empirical application demonstrating the hypothesized interaction effects, see Finkel \& Foshee, 2006).

Third, although the Impelling/Inhibiting Model explicitly recognizes that relational factors influence violence-impelling and violenceinhibiting forces (see Figure 1), this report has not dealt with dyadic processes as they play out during a given interaction between romantic partners. Certain partner behaviors will surely influence the degree to which the individual experiences strong versus weak violenceimpelling and violence-inhibiting forces. Research demonstrates that dyadic processes such as negative reciprocity (in which partners become embroiled in an escalating cycle of reciprocated negativity; Cordova, Jacobson, Gottman, Rushe, \& Cox, 1993) and demand/ withdrawal (in which individuals become increasingly demanding of their partner, who withdraws from them; Babcock et al., 1993) predict elevated IPV perpetration. Although these interpersonal processes will likely be mediated in part through situational risk factors such as those listed in Figure 1, they have not been explicitly incorporated into the Impelling/ Inhibiting Model. Likewise, the present report does not examine the interplay between the two partners' characteristics. For example, perhaps witnessing parental violence as a child is a particularly strong predictor of IPV for individuals who are currently romantically involved with a partner who is similar to the individual's opposite sex parent. Investigating such processes would significantly advance both the complexity and the sophistication of the Impelling/Inhibiting Model (and of IPV research more generally).

Fourth, as mentioned briefly above, the literature does not allow for definitive categorization of certain risk factors as contributing either to violence-impelling forces or to violence- inhibiting forces. Many risk factors may be relatively straightforward to categorize based on theoretical grounds. For example, self-control is almost surely best categorized as a violenceinhibiting force. Other risk factors, however, will be more difficult to categorize and will likely influence both forces to varying degrees. For example, I hypothesize that psychopathy (a psychological condition characterized by interpersonal callousness and poor impulse control) primarily weakens violence-inhibiting forces, but it could also strengthen violence-impelling forces. Resolving this categorization ambiguity issue can only be accomplished empirically, and it represents an especially important direction for future research. Scholars in psychology and neuroscience have recently made great strides in distinguishing processes related to impulsive tendencies from processes related to the restraint of those tendencies. For example, researchers investigating prejudice have developed methods to distinguish between these two processes (e.g., Devine, Plant, Amodio, Harmon-Jones, \& Vance, 2002; Monteith, 1993; Monteith, Ashburn-Nardo, Voils, \& Czopp, 2002), as have researchers investigating the distinct functions of various parts of the brain (e.g., Damasio, 1994; Richeson et al., 2003). Future research can build on these advances toward the goal of discerning empirically the degree to which a given risk factor functions by strengthening violence-impelling forces, by weakening violence-inhibited forces, or by doing both.

Fifth, an issue to be resolved empirically involves determining when acts of IPV are due to self-regulatory failure and when they are due to strategic self-regulatory tactics designed to achieve specific long-term goals. In advancing hypotheses regarding this issue, it is instructive for scholars to consider the long-standing distinction in the psychological literature between hostile and instrumental aggression (cf. Feshbach, 1964). Hostile aggression is a "'hot,' impulsive behavior that is motivated by a desire to hurt someone," whereas instrumental aggression is "“cold,' premeditated behavior used as a means to some other end" (Bushman \& Anderson, 2001, p. 273). Although the field is moving away from the notion that there is an either/or dichotomy between these two types of aggression (Bushman \& Anderson, 2001), the distinction is still valuable in conceptualizing those factors that can serve as instigating 
triggers to violent behavior. Instrumental instigating triggers include controlling the partner's behavior, gaining justice or retribution, promoting or defending one's self-image, and trying to improve one's mood (e.g., Bushman, Baumeister, \& Phillips, 2001; Felson, 1993, 2002). Hostile instigating triggers include partner or thirdparty provocation, conflict, or goal obstruction (e.g., Berkowitz, 1990, 1993; Dollard et al., 1939; Pederson, Gonzales, \& Miller, 2000). Future research could investigate the hypothesis that self-regulatory failure is a crucial (perhaps the crucial) antecedent of those acts of IPV instigated preponderantly by hostile triggers (see Baumeister \& Boden, 1998), but not of those acts of IPV instigated preponderantly by instrumental triggers. In fact, one could even hypothesize that preponderantly instrumentally triggered violence could be facilitated by effective self-regulation, for example, by steeling one's nerve to be as brutal as necessary to accomplish one's goals. Shakespeare's Lady Macbeth provides a compelling illustration when she exhorts her husband to conquer his wobbly resolve about committing cold-blooded murder to achieve their goals: "But screw your courage to the sticking-place,/And we'll not fail" (Macbeth, Act 1, Scene 7). Although Lady Macbeth provides a vivid example of circumstances where effective self-regulation can make individuals more violent, I hypothesize that self-regulatory failure is a more common culprit in IPV perpetration than is selfregulatory success.

Sixth, and finally, although the Impelling/ Inhibiting Model makes a number of distinctions, it does not yet distinguish between risk factors that exert their effects via motivationrelevant versus ability-relevant pathways. This distinction could be useful, for example, in understanding the differences between psychopathy and low self-control, which are both hypothesized to weaken violence-inhibiting forces. Psychopathy is hypothesized to weaken them primarily by diminishing individuals' motivation to override violent impulses, whereas low self-control is hypothesized to do so primarily by diminishing individuals' ability to override these impulses. Individuals characterized by strong psychopathy tend not to care very much about the pain and suffering they cause others. Many individuals characterized by low selfcontrol, in contrast, do care about the pain and suffering they cause others, but they lack the strategies, skills, and strength necessary to control their violent impulses effectively. Whereas individuals high in psychopathy are unlikely to experience remorse about hurting a partner (unless it results in negative outcomes for the themselves), those low in self-control could well experience a great deal of remorse.

\section{Conclusions}

Intimate partner violence is a serious societal problem and a fascinating scientific one. The past three decades have witnessed an explosion of research on IPV, effectively establishing perpetration rates and risk factors. Theory development has lagged behind. The goals of this report have been to (a) propose a process model of IPV perpetration that emphasizes the importance of restraining violent impulses and (b) impose increased theoretical coherence on IPV risk factors.

Before closing, I briefly revisit the spousal conflict scenario that opened this article. It is important to note that Spouse A placing the lamp back on the table and exiting the house while yelling obscenities likely means that Spouse B has been the victim of verbal and psychological abuse. Hopefully, Spouses A and B will ultimately develop the communication and anger management skills to avoid furyinfused conflict altogether. In the meantime, however, having Spouse A leave the situation without physically assaulting Spouse B is a large step in the right direction.

\section{References}

Anderson, C. A., \& Bushman, B. J. (2002). Human aggression. Annual Review of Psychology, 53, 2751.

Archer, J. (2000). Sex differences in aggression between heterosexual partners: A meta-analytic review. Psychological Bulletin, 126, 651-680.

Archer, J. (2006). Cross-cultural differences in physical aggression between partners: A social role analysis. Personality and Social Psychology Review, 10, 133-153.

Averill, J. R., (1982). Anger and aggression: An essay on emotion. New York: Springer.

Babcock, J. C., Green, C. E., Robie, C. (2004). Does batterers' treatment work? A meta-analytic review of domestic violence treatment. Clinical Psychology Review, 23, 1023-1053. 
Babcock, J. C., Waltz, J., Jacobson, N. S., \& Gottman, J. M. (1993). Power and violence: The relation between communication patterns, power discrepancies, and domestic violence. Journal of Consulting and Clinical Psychology, 61, 40-50.

Bandura, A. (1973). Aggression: A social learning analysis. Englewood Cliffs: NJ: Prentice Hall.

Baron, R. A., \& Richardson, D. R. (1994). Human aggression (2nd ed.). New York: Plenum Press.

Bartholomew, K., \& Allison, C. J. (2006). An attachment perspective on abusive dynamics in intimate relationships. In M. Mikulincer \& G. S. Goodman (Eds.), Dynamics of romantic love: Attachment, caregiving, and sex (pp. 102-127). New York: Guilford Press.

Baumeister, R. F. (2005). The cultural animal: Human nature, meaning, and social life. New York: Oxford.

Baumeister, R. F., \& Boden, J. M. (1998). Aggression and the self: High self-esteem, low selfcontrol, and ego threat. In R. G. Geen \& E. Donnerstein (Eds.), Human aggression: Theories, research, and implications of social policy (pp. 111-137). Boston: Academic Press.

Baumeister, R. F., Heatherton, T. F., \& Tice, D. M. (1994). Losing control: How and why people fail at self-regulation. New York: Academic Press.

Baumeister, R. F., \& Vohs, K. D. (2004). Handbook of self-regulation: Research, theory, and applications. New York: Guilford Press.

Berkowitz, L. (1990). On the formation and regulation of anger and aggression: A cognitiveneoassociationistic analysis. American Psychologist, 45, 494-503.

Berkowitz, L. (1993). Aggression: Its causes, consequences, and control. New York: McGraw-Hill.

Berscheid, E., \& Regan, P. (2005). The psychology of interpersonal relationships. New York: Prentice Hall.

Bettencourt, B. A., Talley, A., Benjamin, A. J., \& Valentine, J. (2006). Personality and aggressive behavior under provoking and neutral conditions: A meta-analytic review. Psychological Bulletin, 132, 751-777.

Bureau of Justice Statistics. (1997). Sex differences in violent victimization, 1994. Washington, DC: U.S. Government Printing Office.

Bushman, B. J., \& Anderson, C. A. (2001). Is it time to pull the plug on the hostile versus instrumental aggression typology? Psychological Review, 108, 273-279.

Bushman, B. J., Baumeister, R. F., \& Phillips, C. M. (2001). Do people aggress to improve their mood? Catharsis beliefs, affect regulation opportunity, and aggressive responding. Journal of Personality and Social Psychology, 81, 17-32.

Cordova, J. V., Jacobson, N. S., Gottman, J. M., Rushe, R., \& Cox, G. (1993). Negative reciprocity and communication in couples with a violent husband. Journal of Abnormal Psychology, 102, 559564.

Damasio, A. R. (1994). Descartes' error: Emotion, reason and the human brain. New York: Grosset/ Putnam.

Devine, P. G., Plant, E. A., Amodio, D. M., HarmonJones, E., \& Vance, S. L. (2002). The regulation of explicit and implicit race bias: The role of motivations to respond without prejudice. Journal of Personality and Social Psychology, 82, 835-848.

DeWall, C. N., Baumeister, R. F., Gailliot, M. T., \& Stillman, T. (2007). Violence restrained: Effects of self-regulatory capacity and its depletion on aggressive behavior. Journal of Experimental Social Psychology, 43, 62-76.

Dobash, R. E., \& Dobash, R. P. (1979). Violence against wives: A case against the patriarchy. New York: Free Press.

Dodge, K. A., \& Coie, J. D. (1987). Social information-processing factors in reactive and proactive aggression in children's playgroups. Journal of Personality and Social Psychology, 53, 11461158.

Dollard, J., Doob, L. W., Miller, N. E., Mowrer, O. H., \& Sears, R. R. (1939). Frustrations and aggression. New Haven: Yale University Press.

Dutton, D. G., \& Corvo, K. (2006). Transforming a flawed policy: A call to revive psychology and science in domestic violence research and practice. Aggression and Violent Behavior, 11, 457-483.

Eckhardt, C. I., Barbour, K. A., \& Davison, G. C. (1998). Articulated thoughts of maritally violent and nonviolent men during anger arousal. Journal of Consulting and Clinical Psychology, 66, 259269.

Eckhardt, C. I., \& Dye, M. L. (2000). The cognitive characteristics of maritally violent men: Theory and evidence. Cognitive Therapy and Research, 24, 139-158.

Ehrensaft, M. K., Moffitt, T. E., Caspi, A. (2004). Clinically abusive relationships in an unselected birth cohort: Men's and women's participation and developmental antecedents. Journal of Abnormal Psychology, 113, 258-271.

Fals-Stewart, W. (2003). The occurrence of partner physical aggression on days of alcohol consumption: A longitudinal diary study. Journal of Consulting and Clinical Psychology, 71, 41-52.

Felson, R. B. (1984). Patterns of aggressive social interaction. In A. Mummendey (Ed.), Social psychology of aggression: From individual behavior to social interaction (pp. 107-126). New York: Springer-Verlag.

Felson, R. B. (1993). Predatory and dispute-related violence: A social interactionist approach. In R. V. Clarke \& M. Felson (Eds.), Advances in crimino- 
logical theory (Vol. 5, pp. 189-235). New Brunswick, NJ: Transaction.

Felson, R. B. (2002). Violence and gender reexamined. Washington, DC: American Psychological Association.

Felson, R. B., Ackerman, J., \& Yeon, S. (2003). The infrequency of family violence. Journal of Marriage and the Family, 65, 622-634.

Feshbach, S. (1964). The function of aggression and the regulation of aggressive drive. Psychological Review, 71, 257-272.

Finkel, E. J. (2006). Violent impulses and behavioral restraint in intimate partner violence. Unpublished manuscript, Northwestern University.

Finkel, E. J., \& Campbell, W. K. (2001). Self-control and accommodation in close relationships: An interdependence analysis. Journal of Personality and Social Psychology, 81, 263-277.

Finkel, E. J., \& Foshee, V. A. (2006). An empirical test of the impelling/inhibiting model of intimate partner violence. Unpublished manuscript, Northwestern University, IL.

Gaertner, L., \& Foshee, V. (1999). Commitment and the perpetration of relationship violence. Personal Relationships, 6, 227-239.

Giancola, P. R. (2000). Executive functioning: A conceptual framework for alcohol-related aggression. Experimental and Clinical Psychopharmacology, 8, 576-597.

Gottfredson, M. R., \& Hirschi, T. (1990). A general theory of crime. Stanford, CA: Stanford University Press.

Hazan, C., \& Shaver, P. (1987). Conceptualizing romantic love as an attachment process. Journal of Personality and Social Psychology, 52, 511-524.

Holmes, J. G., \& Murray, S. L. (1996). Conflict in close relationships. In E. T. Higgins \& A. Kruglanski (Eds.), Social psychology: Handbook of basic mechanisms and processes (pp. 622-654). New York: Guilford Press.

Holtzworth-Munroe, A., \& Hutchinson, G. (1993). Attributing negative intent to wife behavior: The attributions of maritally violent versus nonviolent men. Journal of Abnormal Psychology, 102, 206211.

Hotaling, G. T., \& Sugarman, D. B. (1986). An analysis of risk markers in husband to wife violence: The current state of knowledge. Violence and Victims, 1, 101-124.

Huesmann, L. R. (1988). An information processing model for the development of aggression. Aggressive Behavior, 14, 13-24.

Johnson, M. P. (1995). Patriarchal terrorism and situational couple violence: Two forms of violence against women. Journal of Marriage and the Family, 57, 283-294.
Johnson, M. P. (in press). Violence and control in intimate relationships: Intimate terrorism and other types of domestic violence.

Johnson, M. P., \& Ferraro, K. J. (2000). Research on domestic violence in the 1990s: Making distinctions. Journal of Marriage \& the Family, 62, $948-$ 963.

Kandel, D. B., \& Davies, M. (1982). Epidemiology of depressive mood in adolescents: An empirical study. Archives of General Psychiatry, 39, 12051212.

Karney, B. R., \& Bradbury, T. N. (2000). Attributions in marriage: State or trait? A growth curve analysis. Journal of Personality and Social Psychology, 78, 295-309.

Kaufman Kantor, G., Jasinski, J. L., \& Aldarondo, E. (1994). Sociocultrual status and incidence of marital violence in Hispanic families. Violence and Victims, 9, 207-222.

Kwong, M. J., Bartholomew, K., Henderson, A. J. Z., \& Trinke, S. J. (2003). The intergenerational transmission of relationship violence. Journal of Family Psychology, 17, 288-301.

Magdol, L., Moffitt, T. E., Caspi, A., Newman, D. L., Fagan, J., \& Silva, P. A. (1997). Gender differences in partner violence in a birth cohort of 21year-olds: Bridging the gap between clinical and epidemiological approaches. Journal of Consulting and Clinical Psychology, 65, 68-78.

McLaughlin, I. G., Leonard, K. E., \& Senchak, M. (1992). Prevalence and distribution of premarital aggression among couples applying for a marriage license. Journal of Family Violence, 7, 309-319.

Metcalfe, J., \& Mischel, W. (1999). A hot/coolsystem analysis of delay of gratification: Dynamics of willpower. Psychological Review, 106, 3-19.

Monteith, M. J. (1993). Self-regulation of prejudiced responses: Implications for progress in prejudicereduction efforts. Journal of Personality and Social Psychology, 65, 469-485.

Monteith, M. J., Ashburn-Nardo, L., Voils, C. I., \& Czopp, A. M. (2002). Putting the brakes on prejudice: On the development and operation of cues for control. Journal of Personality and Social Psychology, 83, 1029-1050.

Muraven, M., \& Baumeister, R. F. (2000). Selfregulation and depletion of limited resources: Does self-control resemble a muscle? Psychological Bulletin, 126, 247-259.

Murphy, C. M., \& O’Leary, K. D. (1989). Psychological aggression predicts physical aggression in early marriage. Journal of Consulting and Clinical Psychology, 57, 579-582.

Norlander, B., \& Eckhardt, C. (2005). Anger, hostility, and male perpetrators of intimate partner violence: A meta-analytic review. Clinical Psychology Review, 25, 119-152. 
Pederson, W. C., Gonzales, C., \& Miller, N. (2000). The moderating effect of trivial triggering provocation on displaced aggression. Journal of Personality and Social Psychology, 78, 913-927.

Richeson, J. A., Baird, A. A., Gordon, H. L., Heatherton, T. F., Wyland, C. L., Trawalter, S., et al. (2003). An fMRI investigation of the impact of interracial contact on executive control. Nature Neuroscience, 6, 13231328.

Ronfeldt, H. M., Kimerling, R., \& Arias, I. (1998). Satisfaction with relationship power and the perpetration of dating violence. Journal of Marriage and the Family, 60, 70-78.

Runciman, W. G. (1966). Relative deprivation and social justice. London: Routledge \& Kegan Paul.

Schafer, J., Caetano, R., \& Clark, C. L. (1998). Rates of intimate partner violence among U.S. couples. American Journal of Public Health, 88, 17021704.

Schumacher, J. A., Feldbau-Kohn, S., Slep, A. M. S., \& Heyman, R. E. (2001). Risk factors for male-tofemale partner physical abuse. Aggression and $\mathrm{Vi}$ olent Behavior, 6, 281-352.

Steele, C. M., \& Josephs, R. A. (1990). Alcohol myopia: Its prized and dangerous effects. American Psychologist, 45, 921-933.

Stets, J. E. (1990). Verbal and physical aggression in marriage. Journal of Marriage and the Family, 52, 501-514.

Stets, J. E., \& Pirog-Good, M. A. (1987). Violence in dating relationships. Social Psychology Quarterly, 50, 237-246.

Stith, S. M., Rosen, K. H., Middleton, K. A., Busch, A. L., Lundeberg, K., \& Carlton, R. P. (2000). The intergenerational transmission of spouse abuse: A meta-analysis. Journal of Marriage and the Family, 62, 640-654.
Straus, M. A. (1999). The controversy over domestic violence by women: A methodological, theoretical, and sociology of science analysis. In X. B. Arriaga \& S. Oskamp (Eds.), Violence in intimate relationships (pp. 17-44). Thousand Oaks, CA: Sage.

Straus, M. A. (2004). Cross-cultural reliability and validity of the revised conflict tactics scales: A study of university student dating couples in 17 nations. Cross-Cultural Research: The Journal of Comparative Social Science, 38, 407-432.

Straus, M. A., \& Gelles, R. J. (1986). Societal change and change in family violence from 1975 to 1985 as revealed by two national surveys. Journal of Marriage and the Family, 48, 465-479.

Straus, M. A., Gelles, R. J., \& Steinmetz, S. K. (1980). Behind closed doors. Newbury Park, CA: Sage.

Straus, M. A., Hamby, S. L., Boney-McCoy, S., \& Sugarman, D. B. (1996). The revised conflict tactics scales (CTS2). Journal of Family Issues, 17, 283-316.

Tavris, C. (1989). Anger: The misunderstood emotion. New York: Simon \& Schuster.

Thibaut, J. W., \& Kelley, H. H. (1959). The social psychology of groups. New York: Wiley.

Tjaden, P., \& Thoennes, N. (2000). Extent, nature, and consequences of intimate partner violence: Findings from the National Violence Against Women Survey. Washington, DC: National Institute of Justice.

Walker, I., \& Smith, H. J. (2002). Relative deprivation: Specification, integration, and development. Cambridge: Cambridge University Press.

Received January 27, 2006

Revision received November 27, 2006 Accepted November 28, 2006 